\title{
BMJ
}

\section{Life expectancy in relation to cardiovascular risk factors: 38 year follow-up of 19000 men in the Whitehall study}

\author{
Robert Clarke, reader in epidemiology and public health medicine, ${ }^{1}$ Jonathan Emberson, senior statistician, \\ Astrid Fletcher, professor of epidemiology, ${ }^{2}$ Elizabeth Breeze, lecturer in epidemiology, ${ }^{3}$ Michael Marmot, \\ professor of epidemiology and public health medicine, ${ }^{3}$ Martin J Shipley, senior lecturer in medical statistics ${ }^{3}$
}

${ }^{1}$ Clinical Trial Service Unit and Epidemiological Studies Unit (CTSU), Richard Doll Building, University of Oxford, Oxford OX3 7LF

${ }^{2}$ London School of Hygiene and Tropical Medicine, London WCIE 6HT

${ }^{3}$ Department of Epidemiology and Public Health, University College London Medical School, London WCIE 6BT

Correspondence to: $\mathrm{R}$ Clarke robert.clarke@ctsu.ox.ac.uk

Cite this as: $B M J$ 2009;339:b3513 doi:10.1136/bmj.b3513

\section{ABSTRACT}

Objective To assess life expectancy in relation to cardiovascular risk factors recorded in middle age. Design Prospective cohort study.

Setting Men employed in the civil service in London, England.

Participants 18863 men examined at entry in 1967-70 and followed for 38 years, of whom 13501 died and 4811 were re-examined in 1997.

Main outcome measures Life expectancy estimated in relation to fifths and dichotomous categories of risk factors (smoking, "low" or "high" blood pressure ( $\geq 140 \mathrm{~mm} \mathrm{Hg}$ ), and "low" or "high" cholesterol ( $\geq 5 \mathrm{mmol}$ ) l)), and a risk score from these risk factors.

Results At entry, $42 \%$ of the men were current smokers, $39 \%$ had high blood pressure, and 51\% had high cholesterol. At the re-examination, about two thirds of the previously "current" smokers had quit smoking shortly after entry and the mean differences in levels of those with high and low levels of blood pressure and cholesterol were attenuated by two thirds. Compared with men without any baseline risk factors, the presence of all three risk factors at entry was associated with a 10 year shorter life expectancy from age 50 ( 23.7 v 33.3 years). Compared with men in the lowest $5 \%$ of a risk score based on smoking, diabetes, employment grade, and continuous levels of blood pressure, cholesterol concentration, and body mass index (BMI), men in the highest $5 \%$ had a 15 year shorter life expectancy from age $50(20.2 v 35$. 4 years).

Conclusion Despite substantial changes in these risk factors over time, baseline differences in risk factors were associated with 10 to 15 year shorter life expectancy from age 50 .

\section{INTRODUCTION}

Mortality rates from cardiovascular diseases in the United Kingdom have declined steadily since their peak levels in the early $1970 \mathrm{~s},{ }^{12}$ as have mortality rates from non-vascular causes, resulting in substantial improvements in life expectancy. These improvements are mainly attributable to population-wide changes in the three main cardiovascular risk factors (cigarette smoking, raised cholesterol concentration, and high blood pressure) and to better treatment of individuals with pre-existing vascular disease. ${ }^{3-5}$ The Whitehall study of 19019 male civil servants in London-who were aged 40-69 when first examined in 1967-70 - was set up at the peak of the vascular disease epidemic in the UK to assess the importance of risk factors for prediction of coronary and vascular mortality. ${ }^{67}$ The initial results were used by the late Geoffrey Rose to assess "high risk" and "population" approaches that have guided public health strategies for the prevention of cardiovascular disease. ${ }^{8}$

After nearly 40 years of follow-up for cause specific mortality, the Whitehall study provides a rare opportunity to estimate the impact of differences in cardiovascular risk factors measured during middle age on life expectancy. We had three aims: to compare trends in vascular and non-vascular mortality in the Whitehall study with those in the UK population as a whole; to estimate life expectancy from age 50 in UK men in relation to single baseline measurements of the three main vascular risk factors (smoking, blood pressure, and cholesterol concentration), alone and in combination; and to estimate life expectancy in relation to a more accurate characterisation of cardiovascular risk factors, including, in addition to the three main cardiovascular risk factors, diabetes, body mass index (BMI), and employment grade.

\section{METHODS}

UK mortality trends

Annual cause specific UK mortality rates from 1950 to 2005 were obtained from the World Health Organization and standardised for the mean of the component five year age groups for deaths occurring at age 35-69 (middle age) and 70-79 (old age) (www.mortalityfroms moking.com). The age standardised mortality rates were estimated separately for vascular and non-vascular causes for men and women in these age groups.

\section{Whitehall study population}

Data were collected from 19019 men aged 40-69 who were working in the civil service in London when they were first examined between September 1967 and January $1970 .{ }^{67}$ Participation in the study involved the 
completion of a questionnaire and a medical examination to record height, weight, and blood pressure; to undergo electrocardiography and lung function tests; and to have a blood sample collected for measurement of blood total cholesterol and glucose concentrations. The questionnaire included questions about symptoms, medical history, smoking habits, civil service employment grade, and marital status. Employment grades were categorised into three groups: administrative, professional, or executive; clerical; and other unskilled manual jobs. The employment grade of the 886 men who worked in the Diplomatic Service and British Council was not comparable with the rest of the study participants, and hence these men were excluded from any analyses of employment grade.

At study entry, a trained study nurse measured blood pressure once in the left arm with the London School of Hygiene sphygmomanometer. The nurse recorded systolic blood pressure at the first appearance of the arterial flow sounds. Height (in shoes) and weight were measured and BMI $\left(\mathrm{kg} / \mathrm{m}^{2}\right)$ calculated. Blood samples were collected from the ear lobe into $2 \mathrm{~mm}$ glass tubing. Blood total cholesterol concentration was measured with a Technicon method and blood glucose was measured by a ferricyanide reduction method. All participants (except those with self reported diabetes) had blood glucose measured two hours after drinking a dextrose drink. Those with a glucose concentration of $11.1 \mathrm{mmol} / \mathrm{l}$ or greater were classified as having newly diagnosed diabetes, and those with concentrations of 5.3-11.0 mmol/l were classified as having glucose intolerance.

\section{Ascertainment of cause specific mortality}

Using the procedures of the Office for National Statistics, we traced and flagged the records of 18863 men (99.2\% of cohort members) and identified deaths up to 30 September 2005. Among the 13501 who died, 11317 (83.8\%) deaths were coded according to ICD8 (international classification of diseases, eighth revision), $831(6.2 \%)$ according to ICD-9, and 1353 $(10.0 \%)$ according to ICD-10. Deaths from cancer were classified into groups that have previously been shown ${ }^{9}$ to be probably related to cigarette smoking (lung, stomach, pancreas, bladder, upper aerodigestive (including oesophagus), kidney, myeloid leukaemia, and liver) and a group for which this was regarded as unlikely. Only 43 deaths were of unknown cause, and these deaths contributed to analyses of total mortality but not to cause specific mortality.

Re-examination of surviving participants in old age After the success of a pilot study of the feasibility of contacting surviving participants in 1995, all 8448 surviving participants were invited to participate in another survey in $1997-8 .^{10}$ A postal questionnaire asked for details of any diagnoses of heart attack, angina, or stroke, medications taken in the past month, smoking status, and last known civil service employment grade. ${ }^{11}$ The 7044 participants who responded $(83 \%)$ were subsequently sent a blood collection kit and asked to attend their local surgery to have a blood sample collected and for blood pressure, height, and weight to be recorded. Non-fasting blood samples were obtained from 5434 men (77\% of respondents), from which blood lipids were successfully measured for $5355(98.5 \%) .{ }^{12}$ We had complete data on blood pressure, blood cholesterol concentration, and BMI from both the initial and later survey for 4811 men.

\section{Statistical analysis}

We estimated cause specific death rates overall and separately by age at risk $(50-59,60-69,70-79$, and $\geq 80)$ and calendar period (1967-79, 1980-9, 1990-9, and 2000-5). Follow-up before the age of 50 contributed only 79 deaths, and we excluded these deaths from all analyses. We estimated associations of age at risk and calendar period with mortality using Cox proportional hazards regression to estimate the hazard ratios associated with a 10 year increase in each of these exposures.

Cox regression was used to estimate the relevance of various baseline risk factors (blood pressure, cholesterol concentration, and BMI (by fifths of their distributions), smoking (never, ex-smoker, pipe/cigar only, current), employment grade, marital status, and glucose intolerance/diabetes (defined as self reported diabetes, newly diagnosed diabetes, or glucose intolerance) to vascular and non-vascular mortality, after adjustment for age at risk and calendar period. The few men with data missing for these characteristics were excluded from these, but not other, calculations. All cause mortality rates for each five year age at risk group were calculated for each level of each risk factor. By using standard life table methods, these age specific mortality rates were used to estimate life expectancy from age 50 (defined as the number of years one is expected to live having survived to age 50) and its standard error.

We dichotomised the three main cardiovascular risk factors: current smoker (yes/no); baseline blood pressure ("high" (systolic blood pressure $\geq 140 \mathrm{~mm} \mathrm{Hg}$ ) or "low") and baseline cholesterol concentration ("high" ( $\geq 5.0 \mathrm{mmol} / \mathrm{l}$ ) or "low"). We then separately estimated vascular and non-vascular mortality and life expectancy from age 50 in each of the eight different combinations of these risk factors. Subsequently, we estimated mortality and life expectancy in relation to an all cause mortality risk score using the three main risk factors (with blood pressure and cholesterol concentration now considered as continuous variables and smoking categorised into four groups) and the three main risk factors with BMI (using both linear and quadratic terms ${ }^{13}$ ), diabetes, and employment grade. The two risk scores were calculated for each individual with no missing values by using the coefficients obtained from Cox proportional hazard models of all cause mortality with the above variables. Hazard ratios and life expectancy were estimated by fifths of the distribution of risk score and, for the full risk model only, for the highest $5 \%$ compared with the lowest $5 \%$ of the 
distribution (to assess an even more extreme categorisation of these risk factors).

Finally, to assess the extent of variation within an individual in risk factors between middle and old age, we estimated the mean levels of risk factors recorded at the survey in 1997 for risk categories defined in 1970. Specifically, we compared the differences $\left(\mathrm{d}_{1}\right)$ between the mean blood pressure, cholesterol concentration, and BMI of those classified as "high" or "low" values at entry with the corresponding differences at the second survey $\left(d_{2}\right)$ (the ratio $d_{2} / d_{1}$ is then the regression dilution ratio over about a 28 year period). We repeated these analyses after excluding men who, at re-survey, reported a history of cardiovascular disease, diabetes mellitus, or cancer or use of medication to lower cholesterol concentration or blood pressure. All statistical analyses were conducted with SAS computer software.

\section{RESULTS}

Trends in vascular and non-vascular mortality rates in UK population

The figure shows the age standardised annual UK mortality rates for vascular and non-vascular causes of death at ages 35-69 between 1950 and 2005. Throughout this period, vascular mortality rates in middle age in men were about twice those in women, peaking in 1970 and declining linearly by about $2 \%$ a year in both sexes (or by almost 70\% between 1970 and 2005). The proportion of deaths attributed to vascular disease in middle age also declined between 1970 and 2005, from about $50 \%$ to $30 \%$ in men and from $40 \%$ to $20 \%$ in women. The figure also shows age standardised mortality rates from vascular and non-vascular causes for men and women aged 70-79. For both sexes, the absolute mortality rates in old age were about fivefold greater than those in middle age. In old age, vascular mortality rates declined by about two thirds between 1950 and 2005 in both men and women, but non-vascular mortality rates declined to a much lesser extent in this age group. The proportion of deaths attributed to vascular disease in old age declined from about $60 \%$ in 1950 to less than $40 \%$ in 2005 for both men and women.

Trends in cause specific mortality rates in the Whitehall study

Table 1 shows the age specific death rates and number of deaths from specific causes for men in each decade of age at risk. About a quarter of all deaths occurred before the age of 70 . The median age at death was 76 , and the median time to death 22 years. The proportion of deaths from vascular causes declined with age, ranging from $54 \%$ among those in their 50 s to $45 \%$ among those aged $\geq 80$. The overall mortality rate increased threefold for every 10 year increase in age (hazard ratio per 10 years older $2.95,95 \%$ confidence interval 2.87 to 3.07 ), but mortality rates for stroke and respiratory disease increased over fourfold for every 10 year increase in age.

Table 2 shows the distribution of deaths by calendar period over the 38 year follow-up and the age

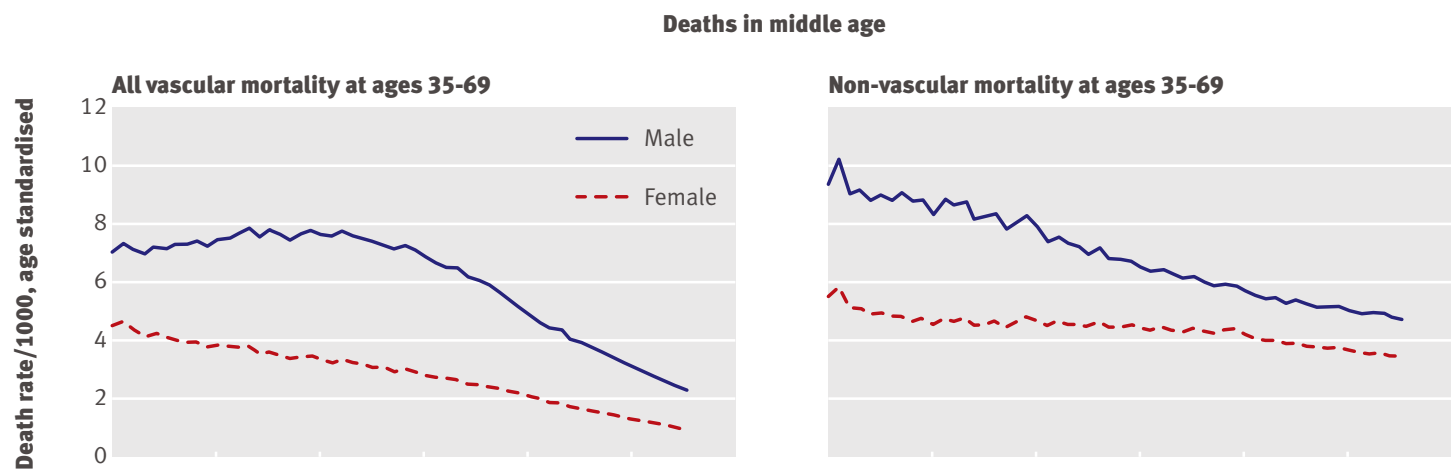

Deaths in old age
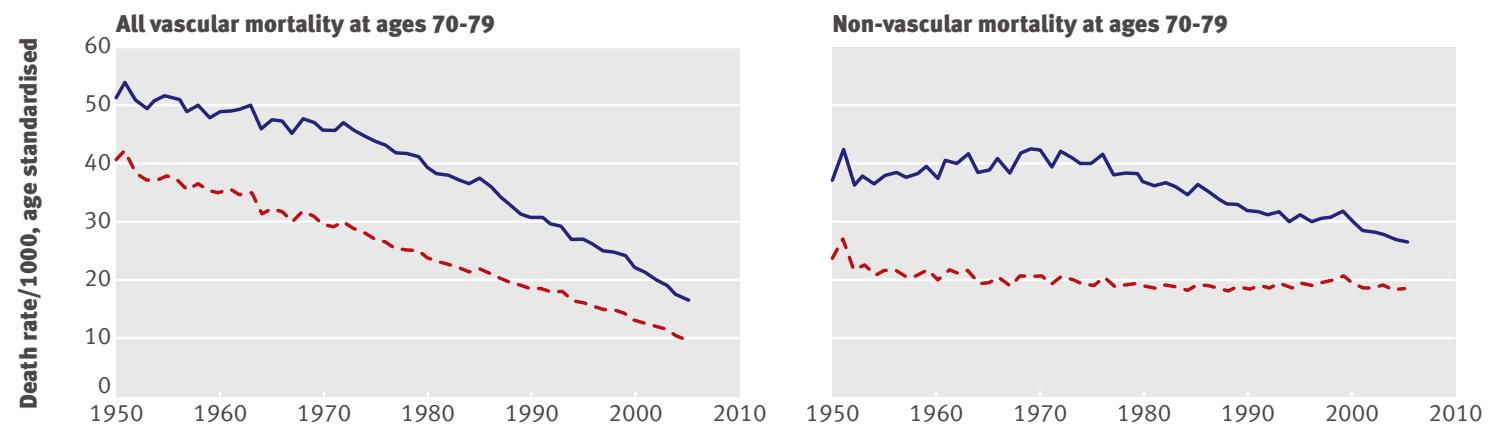

Trends in age standardised vascular and non-vascular mortality (mean of annual rates in component five year age groups) by age and sex for 1950-2005 for UK population (source: WHO and UN population estimates) 
Table 1|Cause specific mortality* by age (years) at death. Figures are rates (number of deaths)

\begin{tabular}{|c|c|c|c|c|c|c|}
\hline Cause of death & $50-59$ & $60-69$ & $70-79$ & $\geq 80$ & All ages & $\mathrm{HR}+$ per 10 years $(95 \% \mathrm{Cl})$ \\
\hline \multicolumn{7}{|l|}{ Vascular disease: } \\
\hline Coronary heart disease & $2.9(338)$ & $6.4(1012)$ & $12.5(1556)$ & $23.9(1126)$ & $9.0(4032)$ & 2.61 (2.49 to 2.74$)$ \\
\hline Stroke & $0.3(35)$ & $1.0(151)$ & $3.6(453)$ & $12.4(583)$ & $2.7(1222)$ & 4.11 (3.76 to 4.50$)$ \\
\hline Other vascular & $0.4(50)$ & $1.2(190)$ & $3.6(444)$ & $9.8(462)$ & $2.6(1146)$ & 3.34 (3.05 to 3.65$)$ \\
\hline All vascular & $3.6(423)$ & $8.5(1353)$ & $19.7(2453)$ & $46.1(2171)$ & $14.3(6400)$ & $2.96(2.85$ to 3.08$)$ \\
\hline \multicolumn{7}{|l|}{ Cancers: } \\
\hline Lung cancer & $0.6(74)$ & $1.8(279)$ & $3.2(393)$ & $3.9(185)$ & $2.1(931)$ & 2.55 (2.31 to 2.81$)$ \\
\hline Colorectal cancer & $0.3(32)$ & $0.7(110)$ & $1.5(189)$ & $2.5(118)$ & $1.0(449)$ & $2.10(1.82$ to 2.43$)$ \\
\hline Bladder cancer & $0.1(6)$ & $0.2(31)$ & $0.6(78)$ & $1.3(63)$ & $0.4(178)$ & 3.35 (2.66 to 4.21$)$ \\
\hline Prostate cancer & $0.0(2)$ & $0.4(63)$ & $1.9(241)$ & $5.1(240)$ & $1.2(546)$ & 3.31 (2.90 to 3.78$)$ \\
\hline Other cancers & $1.1(129)$ & $2.5(395)$ & $4.9(612)$ & $9.2(432)$ & 3.5 (1568) & 1.94 (1.79 to 2.09$)$ \\
\hline Cancers related to smoking & $1.2(146)$ & $3.2(512)$ & $6.4(799)$ & $9.6(453)$ & $4.3(1910)$ & 2.35 (2.19 to 2.51$)$ \\
\hline Cancers not related to smoking & $0.8(97)$ & $2.3(366)$ & $5.7(714)$ & $12.4(585)$ & $3.9(1762)$ & $2.31(2.15$ to 2.48$)$ \\
\hline All cancer & $2.1(243)$ & $5.5(878)$ & $12.2(1513)$ & $22.0(1038)$ & $8.2(3672)$ & 2.33 (2.22 to 2.45$)$ \\
\hline Respiratory & $0.3(41)$ & $1.1(182)$ & $5.0(627)$ & $19.4(916)$ & 3.9 (1766) & 4.57 (4.24 to 4.93$)$ \\
\hline Injuries and suicides & $0.2(29)$ & $0.4(58)$ & $0.5(60)$ & $1.0(48)$ & $0.4(195)$ & $1.81(1.46$ to 2.25$)$ \\
\hline Other causes & $0.4(44)$ & $1.1(170)$ & $3.6(454)$ & $14.4(678)$ & $3.0(1346)$ & 3.56 (3.27 to 3.88$)$ \\
\hline All non-vascular causes & $3.0(357)$ & $8.1(1288)$ & $21.3(2654)$ & $56.9(2680)$ & $15.6(6979)$ & 2.92 (2.85 to 3.06$)$ \\
\hline Unknown cause & $0.1(8)$ & $0.1(8)$ & $0.1(18)$ & $0.2(9)$ & $0.1(43)$ & - \\
\hline All causesł & $6.6(788)$ & $16.7(2649)$ & $41.1(5125)$ & $103.0(4860)$ & 29.9 (13422) & 2.95 (2.87 to 3.07$)$ \\
\hline
\end{tabular}

adjusted hazard ratios for specific causes of death per 10 year increase in calendar period. The secular reductions in vascular and non-vascular mortality rates observed in the Whitehall study were similar to those observed for the UK population as a whole (figure). After adjustment for age at risk, the decline in vascular mortality rates was more than twice that for non-vascular causes (hazard ratio per 10 year calendar period: 0.75 (0.73 to 0.79$)$ for vascular causes and 0.89 (0.86 to 0.93 ) for non-vascular causes). The age adjusted mortality rates for cancers probably related to smoking declined by about $23 \%$ per 10 years, whereas those believed to be unrelated to smoking were unaltered $(0.77$ (0.72 to 0.82$) v 1.03$ (0.96 to1.11), respectively), illustrating the importance of cessation of smoking in this population.

\begin{tabular}{|c|c|c|c|c|c|}
\hline Cause of death & 1967-9* & $1980-9$ & $1990-9$ & $2000-5$ & All periods $\dagger$ \\
\hline \multicolumn{6}{|l|}{ Vascular disease: } \\
\hline Coronary heart disease & 914 & $1243 ; 0.71$ (0.64 to 0.78$)$ & $1316 ; 0.52$ (0.46 to 0.58$)$ & $559 ; 0.38$ (0.32 to 0.43$)$ & 4032; 0.72 (0.69 to 0.76$)$ \\
\hline Stroke & 121 & $312 ; 0.90$ (0.71 to 1.15$)$ & $471 ; 0.66$ (0.51 to 0.85$)$ & $318 ; 0.61$ (0.46 to 0.81 ) & $1222 ; 0.83$ ( 0.77 to 0.91$)$ \\
\hline Other vascular & 148 & $328 ; 0.93$ (0.75 to 1.16$)$ & $432 ; 0.69$ (0.54 to 0.89$)$ & $238 ; 0.58$ (0.44 to 0.77$)$ & $1146 ; 0.81$ (0.75 to 0.89$)$ \\
\hline All vascular & 1183 & $1883 ; 0.76$ (0.70 to 0.83$)$ & $2219 ; 0.56$ (0.51 to 0.61$)$ & $1115 ; 0.44$ (0.39 to 0.50$)$ & $6400 ; 0.75$ ( 0.73 to 0.79$)$ \\
\hline \multicolumn{6}{|l|}{ Cancers: } \\
\hline Lung & 255 & $323 ; 0.61$ (0.51 to 0.73$)$ & $264 ; 0.37$ (0.30 to 0.46$)$ & $89 ; 0.25$ (0.18 to 0.34$)$ & $931 ; 0.62$ (0.56 to 0.68$)$ \\
\hline Colorectal & 80 & $139 ; 0.99$ (0.73 to 1.36$)$ & $155 ; 0.87$ (0.61 to 1.24$)$ & $75 ; 0.86$ (0.56 to 1.32$)$ & $449 ; 0.94$ (0.82 to 1.08$)$ \\
\hline Bladder & 24 & $53 ; 0.80$ (0.47 to 1.38$)$ & $68 ; 0.59$ (0.32 to 1.07$)$ & $33 ; 0.45$ (0.23 to 0.91$)$ & $178 ; 0.76$ (0.61 to 0.94$)$ \\
\hline Prostate & 28 & $136 ; 1.54$ (1.00 to 2.38$)$ & $248 ; 1.57$ (1.00 to 2.45$)$ & $134 ; 1.41$ (0.87 to 2.28$)$ & $546 ; 1.03$ (0.90 to 1.16$)$ \\
\hline Other cancers & 277 & $438 ; 1.02(0.86$ to 1.21$)$ & $593 ; 1.19$ (0.98 to 1.44$)$ & $260 ; 1.06$ (0.84 to 1.33$)$ & $1568 ; 1.04$ (0.96 to 1.12$)$ \\
\hline Cancers related to smoking & 433 & $608 ; 0.73(0.63$ to 0.84$)$ & $620 ; 0.57(0.48$ to 0.67$)$ & $249 ; 0.45$ (0.36 to 0.55$)$ & $1910 ; 0.77$ ( 0.72 to 0.82$)$ \\
\hline Cancers not related to smoking & 231 & $481 ; 1.16$ (0.97 to 1.39$)$ & $708 ; 1.26$ (1.04 to 1.53$)$ & $342 ; 1.14$ (0.91 to 1.43$)$ & $1762 ; 1.03$ (0.96 to 1.11$)$ \\
\hline All cancer & 664 & $1089 ; 0.87$ (0.78 to 0.97$)$ & $1328 ; 0.80$ (0.70 to 0.90$)$ & $591 ; 0.68$ (0.58 to 0.79$)$ & $3672 ; 0.88$ (0.84 to 0.93 ) \\
\hline Respiratory & 151 & $391 ; 0.83$ (0.67 to 1.03$)$ & $769 ; 0.73(0.58$ to 0.91$)$ & $455 ; 0.56(0.44$ to 0.71$)$ & $1766 ; 0.82$ (0.76 to 0.88 ) \\
\hline Injuries and suicides & 52 & $59 ; 0.94$ (0.61 to 1.44$)$ & $53 ; 0.78$ (0.46 to 1.35$)$ & $31 ; 0.78$ (0.40 to 1.53$)$ & $195 ; 0.91$ (0.73 to 1.14$)$ \\
\hline Other causes & 122 & $263 ; 0.95$ (0.74 to 1.22$)$ & $573 ; 1.12$ (0.86 to 1.45$)$ & $388 ; 1.07$ (0.80 to 1.42$)$ & $1346 ; 1.04$ (0.95 to 1.12$)$ \\
\hline Non-vascular & 989 & $1802 ; 0.88$ ( 0.80 to 0.96$)$ & $2723 ; 0.83$ ( 0.75 to 0.91$)$ & $1465 ; 0.70(0.63$ to 0.79$)$ & $6979 ; 0.89$ (0.86 to 0.93$)$ \\
\hline All causesł & 2181 & $3699 ; 0.82$ (0.77 to 0.87$)$ & $4962 ; 0.68$ (0.64 to 0.73$)$ & $2580 ; 0.56(0.52$ to 0.61$)$ & $13422 ; 0.83$ ( 0.81 to 0.85$)$ \\
\hline
\end{tabular}

*Reference category (that is, hazard ratio=1.0).

†Hazard ratios associated with an increase in calendar period of 10 years adjusted for age.

flncludes 43 deaths where specific cause was unknown. 
Comparison between levels of risk factors recorded in middle and old age

Among the 7044 men who completed the questionnaire in 1997, 13\% were current smokers (compared with $40 \%$ of all men in 1967-70) and 58\% were ex-smokers. Of the ex-smokers, the mean age at quitting smoking was 52, an average of 26 years earlier (that is, shortly after entry into the study). In addition, of the men who had been cigarette smokers in 1967-70, just 29\% were still current smokers at re-survey (indicating that over two thirds had quit, for some reason, during that time). Mean blood pressure, cholesterol concentration, and BMI were obtained for 4811 men at re-survey, of whom 1930 had no history of disease or medication to lower blood pressure or cholesterol concentration. The difference between mean levels of systolic blood pressure for men with "high" versus "low" blood pressure at baseline declined by over two thirds (30.6 $v 8.3 \mathrm{~mm} \mathrm{Hg}$ ) between 1967-70 and 1997 in all men with available data (see table A on bmj.com). Similarly, the difference in mean levels between "high" and "low" cholesterol declined by over two thirds (1.86 $v 0.49 \mathrm{mmol} / \mathrm{l})$ over this period in all men (see table A on bmj.com). Differences in BMI between the obese and non-obese groups, however, declined to a lesser extent (9.9 $v 5.6$ ) over this period. Exclusion of men with previous disease or use of medication to lower blood pressure or cholesterol concentration did not materially alter the extent of the observed variability within individuals.

\section{Cardiovascular risk factors and life expectancy}

Table 3 shows the prevalence of the major cardiovascular risk factors at entry and their relation with vascular and non-vascular mortality and life expectancy. In 1967-70, 7919 men (42\%) reported that they were current cigarette smokers and $3502(18 \%)$ reported that they had never smoked tobacco. After adjustment for age and calendar period, the hazard ratios associated with current smoking compared with never smoking were 1.57 (1.46 to 1.69$)$ for vascular mortality and 2.07 (1.92 to 2.22) for non-vascular mortality. Current smoking defined at study entry was associated with an average 6.3 year difference in life expectancy at age 50 compared with non-smoking. As the re-survey of survivors in 1997 indicated that about two thirds of smokers quit smoking within a few years after entry into the study, the observed effects of current smoking for cause specific mortality have probably been underestimated by about 50\% (see appendix on bmj.com).

Table 3 shows that the difference in life expectancy between the highest and lowest fifths of systolic blood pressure was 5.2 years. Even dichotomising blood pressure crudely into two categories, "high" versus "low" blood pressure (corresponding to a "usual" difference in systolic blood pressure of probably about $15 \mathrm{~mm} \mathrm{Hg}$ (see table A on bmj.com) was associated with a hazard ratio of 1.64 (1.56 to 72$)$ for vascular mortality, and 1.09 (1.04 to1.14) for non-vascular mortality and a 3.5 year shorter life expectancy (see table B on bmj.com). "High" cholesterol (corresponding to a "usual" difference in total cholesterol of probably about $0.9 \mathrm{mmol} / \mathrm{l}$; see table $\mathrm{A}$ on bmj.com) was associated with a hazard ratio of 1.24 (1.18 to1.30) for vascular mortality, and a one year shorter life expectancy at age 50 (see table $\mathrm{B}$ on bmj.com). Table 3 shows that difference in life expectancy between the highest and lowest fifths of total cholesterol concentration was 1.9 years. Differences in upper and lower employment grades were associated with 5.4 year difference in life expectancy. Married men had a 2.2 year longer life expectancy than unmarried men (but this association was entirely explained by differences in the other risk factors). Glucose intolerance or diabetes mellitus at baseline (prevalence 6.9\%) was associated with a 3.6 year shorter life expectancy at age 50 .

\section{Associations of life expectancy with combinations of} cardiovascular risk factors

Table 4 shows the effects of combinations of the three main risk factors for cause specific mortality and life expectancy. The hazard ratios for vascular mortality increased progressively with increasing number of cardiovascular risk factors when compared with men without any of them. Compared with the 17\% of men without any baseline risk factors, men with all three risk factors $(8.3 \%)$ in 1967-70 had a threefold higher vascular mortality rate, a twofold higher non-vascular mortality rate, and a 9.6 year shorter life expectancy from age 50 (23.7 $v 33.3$ years).

Associations of life expectancy with mortality risk scores Classification of men by fifths of a risk score based on four categories of smoking and continuous measures of blood pressure and cholesterol concentration was associated with a 9.3 year difference in life expectancy at age 50 (24.2 $v 33.5$ years) between the highest and lowest fifths (table 5). Additional inclusion of glucose intolerance, employment grade, and BMI was associated with a 10.4 year difference in life expectancy at age 50 (23.6 $v 34.0$ years) between the highest and lowest fifths, and a 15.2 year difference (20.2 $v 35.4$ years) when the highest and lowest $5 \%$ of the distributions were compared (table 5).

\section{DISCUSSION}

Despite the fact that during follow-up many men stopped smoking, and there was also substantial variation in other risk factors, the presence of all three cardiovascular risk factors (smoking, high blood pressure, and high cholesterol concentration) measured on a single occasion in middle age (even when crudely categorised) predicted a threefold higher rate of vascular mortality, a twofold higher rate of non-vascular mortality, and an almost 10 year shorter life expectancy from age 50 compared with none of the risk factors. Categorisation of study participants by fifths of a risk score involving the three main cardiovascular risk factors together with glucose intolerance, employment grade, and BMI was associated with a 10.4 year difference in life expectancy between those in the top 
Table 3 | Hazard ratios for vascular and non-vascular mortality and life expectancy by risk factors at study entry when examined separately

\begin{tabular}{|c|c|c|c|c|c|c|}
\hline \multirow[b]{2}{*}{ Risk factors } & \multirow{2}{*}{$\begin{array}{c}\text { Prevalence } \\
\text { at baseline (\%) }\end{array}$} & \multicolumn{2}{|c|}{ Vascular deaths } & \multicolumn{2}{|c|}{ Non-vascular deaths } & \multirow{2}{*}{$\begin{array}{c}\text { Mean (SE) life expectanc) } \\
\text { at age } 50\end{array}$} \\
\hline & & Deaths & $\mathrm{HR}^{\star}(95 \% \mathrm{Cl})$ & Deaths & $\mathrm{HR}^{\star}(95 \% \mathrm{Cl})$ & \\
\hline \multicolumn{7}{|l|}{ Smoking: } \\
\hline Never smoker & 18.4 & 1019 & 1.0 & 965 & 1.0 & $32.6(0.2)$ \\
\hline Ex-smoker & 36.5 & 2324 & 1.11 (1.03 to 1.20$)$ & 2436 & $1.26(1.17$ to 1.35$)$ & $30.8(0.1)$ \\
\hline Pipe/cigar only & 3.5 & 222 & 1.15 (0.99 to 1.33$)$ & 221 & 1.24 (1.07 to 1.43$)$ & $30.9(0.5)$ \\
\hline Current smoker & 41.7 & 2834 & 1.57 (1.46 to 1.69$)$ & 3352 & 2.07 (1.92 to 2.22$)$ & $26.3(0.1)$ \\
\hline \multicolumn{7}{|l|}{ Systolic blood pressure (fifth): } \\
\hline 1 (lowest) & 20.9 & 970 & 1.0 & 1509 & 1.0 & $31.1(0.2)$ \\
\hline 2 & 20.2 & 1052 & $1.11(1.02$ to 1.21$)$ & 1394 & 0.95 (0.88 to 1.02$)$ & $30.8(0.2)$ \\
\hline 3 & 20.3 & 1266 & $1.36(1.25$ to 1.48$)$ & 1421 & $0.99(0.92$ to 1.07$)$ & $29.8(0.2)$ \\
\hline 4 & 18.0 & 1276 & 1.60 (1.48 to 1.74$)$ & 1240 & $1.02(0.95$ to 1.10$)$ & $28.5(0.2)$ \\
\hline 5 (highest) & 20.7 & 1835 & 2.17 (2.01 to 2.35$)$ & 1412 & 1.11 (1.03 to 1.19$)$ & $25.9(0.2)$ \\
\hline \multicolumn{7}{|l|}{ Cholesterol (fifth) } \\
\hline 1 (lowest) & 18.9 & 1008 & 1.0 & 1338 & 1.0 & $30.0(0.2)$ \\
\hline 2 & 21.1 & 1218 & $1.11(1.02$ to 1.20$)$ & 1449 & 0.99 (0.92 to 1.07$)$ & $29.7(0.2)$ \\
\hline 3 & 19.1 & 1135 & 1.13 (1.04 to 1.23$)$ & 1333 & $1.00(0.93$ to 1.08$)$ & $29.5(0.2)$ \\
\hline 4 & 20.6 & 1309 & 1.20 (1.10 to 1.30$)$ & 1332 & $0.92(0.85$ to 0.99$)$ & $29.3(0.2)$ \\
\hline 5 (highest) & 20.3 & 1507 & 1.49 (1.38 to 1.62$)$ & 1226 & $0.92(0.85$ to 1.00$)$ & $28.1(0.2)$ \\
\hline \multicolumn{7}{|l|}{ BMI: } \\
\hline 1 (lowest) & 21.0 & 1124 & 1.0 & 1644 & 1.0 & $29.0(0.2)$ \\
\hline 2 & 19.5 & 1134 & 0.99 (0.91 to 1.07$)$ & 1313 & $0.77(0.72$ to 0.83$)$ & $30.4(0.2)$ \\
\hline 3 & 20.3 & 1294 & 1.08 (1.00 to 1.17$)$ & 1347 & $0.77(0.71$ to 0.82$)$ & $29.9(0.2)$ \\
\hline 4 & 19.0 & 1296 & 1.15 (1.06 to 1.25$)$ & 1288 & $0.78(0.73$ to 0.84$)$ & $29.4(0.2)$ \\
\hline 5 (highest) & 20.3 & 1550 & 1.41 (1.30 to 1.52$)$ & 1386 & $0.87(0.81$ to 0.94$)$ & $27.7(0.2)$ \\
\hline \multicolumn{7}{|l|}{ Employment grade: } \\
\hline Administrative/professional/executive & 73.4 & 4290 & 1.0 & 4526 & 1.0 & $30.2(0.1)$ \\
\hline Clerical & 16.6 & 1143 & $1.26(1.18$ to 1.35$)$ & 1286 & 1.43 (1.34 to 1.52$)$ & $26.8(0.2)$ \\
\hline Other & 10.0 & 709 & 1.31 (1.20 to 1.42$)$ & 883 & $1.69(1.57$ to 1.82$)$ & $24.8(0.4)$ \\
\hline \multicolumn{7}{|l|}{ Marital status: } \\
\hline Married & 88.0 & 5633 & 1.0 & 6055 & 1.0 & $29.5(0.1)$ \\
\hline Other & 12.0 & 764 & 1.15 (1.07 to 1.24$)$ & 923 & $1.31(1.23$ to 1.41$)$ & $27.3(0.3)$ \\
\hline \multicolumn{7}{|l|}{ Blood glucose: } \\
\hline Normoglycaemic & 93.1 & 5810 & 1.0 & 6418 & 1.0 & $29.5(0.1)$ \\
\hline Glucose intolerant or diabetic & 6.9 & 545 & 1.44 (1.31 to 1.57$)$ & 514 & $1.28(1.17$ to 1.40$)$ & $25.9(0.3)$ \\
\hline
\end{tabular}

compared with the bottom groups (23.6 $v 34.0$ years). More extreme classification of men into the highest $5 \%$ and the lowest $5 \%$ of a risk score that included all available risk factors was associated with a difference of 15.2 years in life expectancy from age 50 .

\section{Strengths and limitations}

The present study has several strengths, including a prospective design, large sample size, availability of repeat measurements between middle and old age, prolonged duration of follow-up, a large number of deaths, and virtually complete mortality follow-up. The "healthy worker" effect of studying an employed cohort working in the civil service, however, accounted for longer life expectancies than in the general population, but this would have had little effect on comparisons of risk factors within the population studied. Furthermore, only men were enrolled in the study and blood lipid data were available only for total cholesterol concentration (rather than cholesterol fractions or apolipoproteins, which are much stronger predictors of vascular mortality than total cholesterol). ${ }^{1214}$ The effects of these factors on mortality might also have been slightly underestimated by the increased use of aspirin, statins, and blood pressure lowering drugs during follow-up (in 1997, 29\% of resurvey participants were taking aspirin, $28 \%$ were taking blood pressure lowering drugs, but only $2 \%$ were taking statins).

In the UK, life expectancy at birth for men has increased from 69.3 in the early 1970 s to 77.0 in 2005. In the Whitehall study, life expectancy at age 50 varied from 24.8 to 30.2 years between the lower and upper employment grades, whereas life expectancy at birth for UK men in the registrar general's classification scheme varied from 72.7 in grade V category to 80 in grade I category. ${ }^{1516}$ We found proportional improvements in cardiovascular and noncardiovascular mortality comparable with those observed for UK men over this period. The absolute 
Table 4 | Hazard ratios for vascular and non-vascular mortality and life expectancy by cardiovascular risk factors at entry when examined in combination

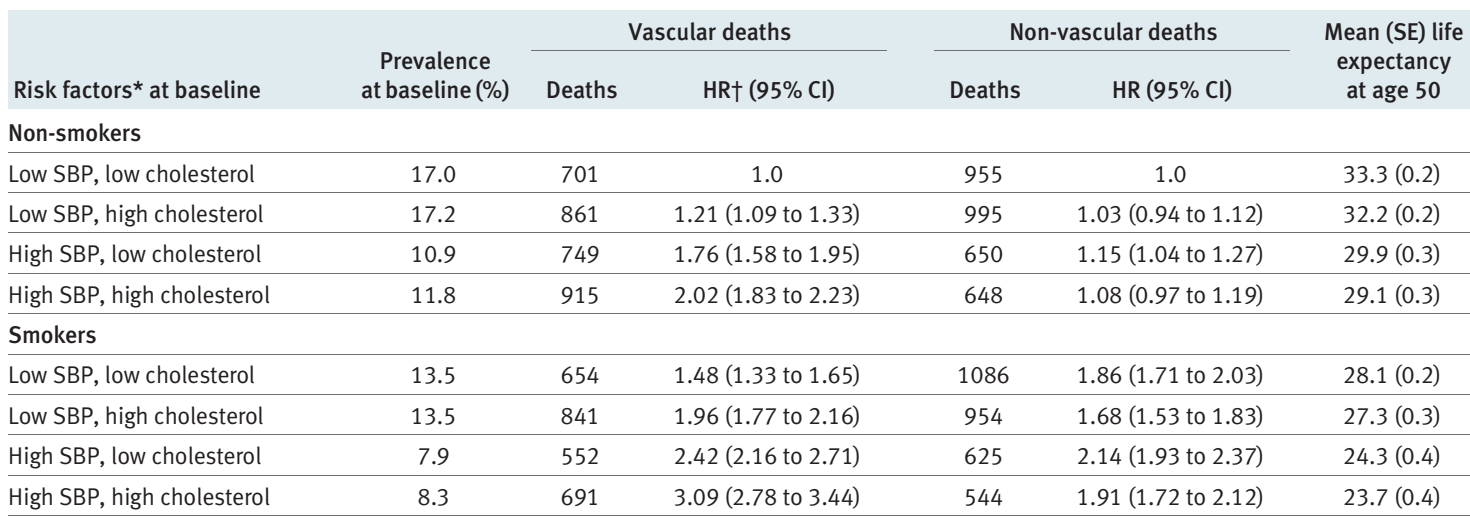

$\mathrm{SBP}=$ systolic blood pressure.

* "Low" blood pressure is $<140 \mathrm{~mm} \mathrm{Hg}$, "low" cholesterol is baseline cholesterol $<5.0 \mathrm{mmol} / \mathrm{l}$.

†Hazard ratios adjusted for age at risk and calendar period.

life expectancy in the Whitehall study cohort, however, was greater than that observed for similar aged men living in England and Wales at this period (probably because of the "healthy worker" effect).

\section{Comparisons with other studies}

Our results confirm that absolute cardiovascular death rates increase exponentially up to the 10th decade of life, similar to the pattern observed in the physicians' health study in the United States over the same period. ${ }^{17}$ Moreover, our results showing the importance of smoking, cholesterol concentration, and blood pressure on life expectancy are concordant with those of the physicians' health study (which also found that smoking, hypertension, diabetes, and obesity accounted for most of the differences in survival to age $90^{18}$ ). As the prevalence of smoking among men in the UK declined steadily between 1970 and 2004 (from about $44 \%$ to $26 \%$ ), ${ }^{16}$ our study will have underestimated the associations with persistent smoking compared with never smoking. The British doctors' study recorded smoking habits each decade over the age of $50^{19}$ and found that current smokers who continued to smoke died on average about 10 years younger than lifelong non-smokers. Moreover, cessation of cigarette smoking at age 60, 50, 40, or 30 years, respectively added about $3,6,9$, or 10 years of life expectancy that they otherwise would have lost if they continued to smoke. ${ }^{19}$

\section{Conclusions and policy implications}

Previous studies in the $\mathrm{UK}^{420}$ and $\mathrm{US}^{21}$ showed that about half of the reduction in coronary deaths between 1980 and 2000 could be attributable to reductions in major risk factors and about half to improvements in medical treatment of people with established vascular disease. Our results provide support for the public health policies aimed at achieving modest changes in

Table 5 | Hazard ratios for vascular and non-vascular mortality and life expectancy by all cause mortality risk scores

\begin{tabular}{|c|c|c|c|c|c|c|}
\hline \multirow[b]{2}{*}{ re catego } & \multirow{2}{*}{$\begin{array}{c}\text { Prevalence } \\
\text { at baseline (\%) }\end{array}$} & \multicolumn{2}{|c|}{ Vascular deaths } & \multicolumn{2}{|c|}{ Non-vascular deaths } & \\
\hline & & Deaths & $\mathrm{HR}^{*}(95 \% \mathrm{Cl})$ & Deaths & $\mathrm{HR}(95 \% \mathrm{Cl})$ & at age \\
\hline
\end{tabular}

Risk score based on SBP, cholesterol, and smoking

\begin{tabular}{lllllll}
\hline 1 (lowest fifth) & 20.0 & 812 & 1.0 & 1044 & 1.0 & $33.5(0.2)$ \\
\hline 2 & 20.0 & 1023 & $1.28(1.17$ to 1.41$)$ & 1240 & $1.23(1.13$ to 1.33$)$ & $31.2(0.2)$ \\
\hline 3 & 20.0 & 1173 & $1.61(1.47$ to 1.76$)$ & 1336 & $1.47(1.35$ to 1.59$)$ & $29.4(0.2)$ \\
\hline 4 & 20.0 & 1292 & $1.91(1.75$ to 2.09$)$ & 1387 & $1.66(1.53$ to 1.80$)$ & $27.6(0.2)$ \\
\hline 5 (highest fifth) & 20.0 & 1583 & $2.74(2.51$ to 2.98$)$ & 1353 & $1.94(1.78$ to 2.10$)$ & $24.2(0.2)$
\end{tabular}

Risk score based on SBP, cholesterol, smoking, BMI, grade, glucose intolerance, and diabetes

\begin{tabular}{lcccccc}
\hline 1 (lowest fifth) & 20.0 & 782 & 1.0 & 977 & 1.0 & $34.0(0.2)$ \\
\hline 2 & 20.0 & 1007 & $1.35(1.23$ to 1.49$)$ & 1223 & $1.34(1.23$ to 1.45$)$ & $31.3(0.2)$ \\
\hline 3 & 20.0 & 1181 & $1.71(1.56$ to 1.87$)$ & 1260 & $1.50(1.38$ to 1.63$)$ & $29.8(0.2)$ \\
\hline 4 & 20.0 & 1361 & $2.17(1.98$ to 2.37$)$ & 1390 & $1.86(1.71$ to 2.02$)$ & $26.9(0.2)$ \\
\hline 5 (highest fifth) & 20.0 & 1552 & $2.85(2.60$ to 3.11$)$ & 1510 & $2.41(2.22$ to 2.62$)$ & $23.6(0.3)$ \\
\hline Lowest $5 \%$ & 5.0 & 154 & 1.0 & 228 & 1.0 & $35.4(0.4)$ \\
\hline Middle $90 \%$ & 90.0 & 5276 & $2.18(1.86$ to 2.56$)$ & 5784 & $1.68(1.47$ to 1.92$)$ & $29.3(0.1)$ \\
\hline Highest $5 \%$ & 5.0 & 453 & $4.65(3.86$ to 5.60$)$ & 348 & $2.70(2.28$ to 3.20$)$ & $20.2(0.6)$
\end{tabular}




\section{WHAT IS ALREADY KNOWN ON THIS TOPIC}

There has been uncertainty about the limits of life expectancy and the relevance of cardiovascular risk factors for prediction of life expectancy

\section{WHAT THIS STUDY ADDS}

Despite substantial variability within individuals in levels of cardiovascular risk factors, the presence of three major risk factors (smoking, high blood pressure, and high cholesterol concentration) recorded on a single occasion in middle aged men was associated with a 10 year shorter life span from age 50 ( $23.7 v 33.3$ years) compared men with none of them

More extreme categorisation of these risk factors including BMI, diabetes mellitus/glucose intolerance, and employment grade was associated with a 15 year difference in life expectancy from age 50 ( 20.2 v 35.4 years)

Continued public health strategies to lower these risk factors could result in further improvements in life expectancy
5 Hardoon SL, Whincup PH, Lennon LT, Wannamethee SG, Capewell S, Morris RW. How much of the recent decline in the incidence of myocardial infarction in British men can be explained by changes in cardiovascular risk factors? Evidence from a prospective population based study. Circulation 2008;117:598-604.

6 Reid DD, Brett GZ, Hamilton PJS, Jarrett, RJ, Keen H, Rose G. Cardiorespiratory disease and diabetes among middle-aged male civil servants: a study of screening and intervention. Lancet 1974;i:469-73.

7 Rose G, Reid DD, Hamilton PJS, McCartney P, Keen H, Jarrett RJ. Myocardial ischaemia, risk factors and death from coronary heart disease. Lancet 1977; i:105-9.

8 Rose G. Strategy of preventive medicine. Oxford: Oxford University Press, 1992.

9 Doll R, Peto R, Wheatley K, Gray R, Sutherland I. Mortality in relation to smoking: 40 years observations on male British doctors. $B M J$ 1994;309:901-10.

10 Clarke R, Breeze E, Sherliker P, Shipley M, Youngman L, Fletcher A, et al. Design, objectives and lessons from a 25 year follow-up resurvey of survivors in the Whitehall study of London Civil Servants. Epidemiol Community Health 1998;52:364-9.

11 Clarke R, Breeze E, Youngman L, Sherliker P, Linksted P, Shah S, et al. Re-survey of the Whitehall study of London civil servants: changes in risk factors for cardiovascular disease during 29 years of follow-up. Cardiovasc Risk 2000;7:251-7.

12 Clarke R, Emberson JR, Parish S Palmer A, Shipley M, Linksted P, et al. Cholesterol fractions and apolipoproteins as risk factors for heart disease mortality in older men. Arch Intern Med 2007;167:1373-8.

13 Kivimäki M, Ferrie JE, Batty GD, Davey Smith G, Elovainio M, Marmot M, et al. Optimal form of characterising BMI in relation to allcause and cause specific mortality: the original Whitehall study. Obesity 2008;16:1926-32

14 Lewington S, Whitlock G, Clarke R, Sherliker P, Emberson J, Halsey J, et al. Blood cholesterol and vascular mortality by age, sex and blood pressure: a meta-analysis of individual participant data from 61 prospective studies with 55,000 vascular deaths. Lancet 2007;370:1829-39.

15 National Statistics. Inequalities in life expectancy at 65 in UK. London: Office for National Statistics, 2007. www.statistics.gov.uk.

16 Allender S, Peto V, Scarborough P, Boxer A, Rayner M. Coronary heart disease statistics 2006. London: British Heart Foundation, 2006.

17 Driver JA, Djousse L, Logroscino G, Gaziano JM, Kurth T. Incidence of cardiovascular disease and cancer in advanced age: prospective cohort study. BMJ 2008;337:A2467.

18 Yates LB, Djousse L, Kurth T, Buring JE, Gaziano JM. Exceptional longevity in men: modifiable factors associated with survival and function up to age 90 years. Arch Intern Med 2009;168:284-90.

19 Doll R, Peto R, Boreham J, Sutherland I. Mortality in relation to smoking: 50 years' observations on male British doctors. BMJ 2004;328:1519-28.

20 Capewell S, Morrison CE, McMurray JJ. Contributions of modern cardiovascular treatment and risk factors changes to the decline in coronary heart disease mortality in Scotland between 1975 and 1994. Heart 1999;81:380-6.

21 Ford ES, Ajani UA, Croft JB, Critchley JA, Labarthe DR, Kottke TE, et al. Explaining the decrease in US deaths from coronary disease, 19802000. N Engl J Med 2007;356:2388-98.

22 Emberson J, Whincup P, Morris R, Walker M, Ebrahim S. Evaluating the impact of population and high-risk strategies for the primary prevention of cardiovascular disease. Eur Heart J 2004;25:484-91.

23 Beckett NS, Peters R, Fletcher AE, Staessen JA, Liu L, Dumitrascu D, et al. Treatment of hypertension in patients 80 years of age or older. N Engl J Med 2008;358:1887-98.

24 Blood Pressure Lowering Trialists' Collaboration. Effects of different blood pressure lowering regimens on major cardiovascular events; results of prospectively designed overviews of randomised trials. Lancet 2003;362:1527-35.

25 Cholesterol Treatment Trialists' Collaboration. Efficacy and safety of cholesterol-lowering treatment: prospective meta-analysis of data from 90,056 participants in 14 randomised trials of statins. Lancet 2006;366:1267-78.

26 Oeepen J, Vaupel JW. Broken limits to life expectancy. Science 2002;296:1029-30.

Accepted: 9 June 2009 